\title{
Ascosteroside C, a new mitochondrial respiration inhibitor discovered by pesticidal screening using recombinant Saccharomyces cerevisiae
}

\author{
Takuya Suga ${ }^{1,9}$, Yukihiro Asami ${ }^{1,2,9}$, Shohei Hashimoto ${ }^{3}$, Kenichi Nonaka ${ }^{1,2}$, Masato Iwatsuki ${ }^{1,2}$, \\ Takuji Nakashima $^{4}$, Ryohei Sugahara ${ }^{5}$, Takahiro Shiotsuki ${ }^{5}$, Takenori Yamamoto ${ }^{6}$, Yasuo Shinohara ${ }^{6,7}$, \\ Naoya Ichimaru ${ }^{8}$, Masatoshi Murai ${ }^{8}$, Hideto Miyoshi ${ }^{8}$, Satoshi Ōmura ${ }^{2}$ and Kazuro Shiomi ${ }^{1,2}$
}

The Journal of Antibiotics (2015) 68, 649-652; doi:10.1038/ja.2015.43; published online 6 May 2015

Some of the successful insecticides discovered to date have been developed from small molecules that target the mitochondrial respiratory system, such as $\mathrm{NADH}$-quinone oxidoreductase (complex I), succinate-quinone oxidoreductase dehydrogenase (complex II) or ubiquinol-cytochrome $c$ oxidoreductase (complex III) inhibitors and uncouplers. ${ }^{1-4}$ However, the widespread use of insecticides has led to resistance developing in many insect species around the world. The accrual of insecticide resistance is affected by many factors. Resistance caused by genetic mutations is ordinarily due to mechanisms that either decrease the response to the interaction of an insecticide with its target site in mitochondria or decrease in insecticide kinetics, such as absorption, distribution, metabolism and excretion..$^{5-9}$ Therefore, it is important to develop new mitochondrial respiration inhibitors as insecticides, which should allow resistance of the conventional respiration target to be overcome.

Mitochondrial respiration produces ATP, which is transported from matrix to intermembrane space by the ADP/ATP carrier protein (AAC) in the mitochondrial inner membrane. Thus, ATP can be utilized at cytosol. We commenced a screening program to find AAC inhibitors that could function as mitochondrial respiration inhibitors. We prepared Saccharomyces cerevisiae yeast organisms by deleting aac genes and subsequently found that some aac genes of pests were transformed to the $\Delta a a c S$. cerevisiae (soon-to-be-published studies).

We screened microbial culture broths to identify chemicals that specifically inhibit the prepared recombinant $S$. cerevisiae. We consequently isolated a new mitochondrial respiration inhibitor, ascosteroside C (1), produced by the fungal strain FKI-6682 isolated from a soil sample collected in Haha-jima, the Bonin Islands, Tokyo, Japan. In this paper, the taxonomy of the producing fungus, isolation, structure elucidation and biological activity of $\mathbf{1}$, are described.
The internal transcribed spacer (ITS) sequence of strain FKI-6682 was elucidated and deposited at the DNA Data Bank of Japan with accession number LC002782. The ITS sequence of FKI-6682 was compared with sequences in the GenBank database by BLASTN 2.2.28 analysis. ${ }^{10}$ The sequence of FKI-6682 was $92.1 \%$ similar to the sequence of NRRL 5042 (ex-type of Aspergillus flaschentraegeri, GenBank accession number EF652150). The producing strain FKI-6682 was assigned to the genus Aspergillus based on its sequence analysis. One loopful of the strain FKI-6682 grown on an LcA slant (0.1\% glycerol, $0.08 \% \quad \mathrm{KH}_{2} \mathrm{PO}_{4}, 0.02 \% \quad \mathrm{~K}_{2} \mathrm{HPO}_{4}, 0.02 \% \quad \mathrm{MgSO}_{4}$ $7 \mathrm{H}_{2} \mathrm{O}, 0.02 \% \mathrm{KCl}, 0.2 \% \mathrm{NaNO}_{3}$ and $1.5 \%$ agar, $\mathrm{pH} 6.0$ ) was inoculated into a 500-ml Erlenmeyer flask containing $100 \mathrm{ml}$ of a seed culture medium ( $2 \%$ glucose, $0.2 \%$ yeast extract, $0.05 \%$ $\mathrm{MgSO}_{4} \cdot 7 \mathrm{H}_{2} \mathrm{O}, 0.5 \%$ Polypepton (Wako Pure Chemical Industries, Ltd., Osaka, Japan), $0.1 \% \mathrm{KH}_{2} \mathrm{PO}_{4}$ and $0.1 \%$ agar, $\mathrm{pH}$ 6.0) and incubated on a rotary shaker at $27^{\circ} \mathrm{C}$ for 2 days. One milliliter of the seed culture was inoculated into each of the 15 Ulpack 47 (culture bags) (HOKKEN Co. Ltd, Tochigi, Japan) containing a production medium (350 g of water-sodden rice). Static fermentation was continued at $27^{\circ} \mathrm{C}$ for 14 days. The stationary culture was extracted with an equal volume of $50 \%$ ethanol. After filtration, the filtrate was concentrated in vacuo to remove ethanol. The filtrate (61) was applied to an ODS chromatography column (500 $\mathrm{ml}$ resin). After washing with $\mathrm{H}_{2} \mathrm{O}$ (1.5 l), the column was eluted stepwise with $30 \%$ acetonitrile (1.5l), 50\% acetonitrile (1.51), 60\% acetonitrile (1.51), $80 \%$ acetonitrile (1.51) and $100 \%$ acetonitrile. The active compound was eluted with the $80 \%$ acetonitrile eluate, and the solution was concentrated in vacuo to remove acetonitrile. Obtained aqueous solution $(500 \mathrm{ml})$ was extracted with an equal volume of ethyl acetate. The organic layer was concentrated in vacuo to dryness. The

${ }^{1}$ Department of Drug Discovery Sciences, Graduate School of Infection Control Sciences, Kitasato University, Tokyo, Japan; ${ }^{2}$ Kitasato Institute for Life Sciences, Kitasato University, Tokyo, Japan; ${ }^{3}$ Department of Chemistry, School of Science, Kitasato University, Kanagawa, Japan; ${ }^{4}$ Research Organization for Infection Control Sciences, Kitasato University, Tokyo, Japan; ${ }^{5}$ Insect Growth Regulation Research Unit, National Institute of Agrobiological Sciences, Tsukuba, Ibaraki, Japan; ${ }^{6}$ Institute for Genome Research, University of Tokushima, Tokushima, Japan; ${ }^{7}$ Faculty of Pharmaceutical Sciences, University of Tokushima, Tokushima, Japan and ${ }^{8}$ Division of Applied Life Sciences, Graduate School of Agriculture, Kyoto University, Kyoto, Japan

${ }^{9}$ These authors contributed equally to this work.

Correspondence: Professor K Shiomi or Professor S Ōmura, Kitasato Institute for Life Sciences, Kitasato University, 5-9-1 Shirokane, Minato-ku, Tokyo 108-8641, Japan. E-mail: shiomi@lisci.kitasato-u.ac.jp or omuras@insti.kitasato-u.ac.jp

Received 3 February 2015; revised 27 March 2015; accepted 31 March 2015; published online 6 May 2015 
concentrated material (360 mg) was applied to an HPLC (Pegasil ODS, 20 i.d. $\times 250 \mathrm{~mm}$; Senshu Scientific Co. Ltd, Tokyo, Japan) with an isocratic solvent system of $70 \%$ acetonitrile-water solution at a flow rate of $9.0 \mathrm{ml} \mathrm{min}^{-1}$ to give an active fraction $(43.9 \mathrm{mg}$ ). Finally, $15 \mathrm{mg}$ of 1 was separated by preparative TLC with $\mathrm{CHCl}_{3}-\mathrm{CH}_{3} \mathrm{OH}$

Table 1 NMR spectroscopic data for ascosterosides $A$ and $C$ in $\mathrm{CD}_{3} \mathrm{OD}$

\begin{tabular}{|c|c|c|c|c|}
\hline \multirow[b]{2}{*}{ Position } & \multicolumn{2}{|c|}{ Ascosteroside $A^{a}$} & \multicolumn{2}{|c|}{ Ascosteroside C } \\
\hline & $\delta_{C}$ & $\delta_{H}$, mult $(J$ in $\mathrm{Hz})$ & $\delta_{C}$ & $\delta_{H}$, mult $(\mathrm{J}$ in $\mathrm{Hz})$ \\
\hline \multirow[t]{2}{*}{1} & 36.3 & $1.46(\mathrm{~m})$ & 36.2 & $1.47(\mathrm{~m})$ \\
\hline & & $1.88(\mathrm{~m})$ & & $1.88(\mathrm{~m})$ \\
\hline \multirow[t]{2}{*}{2} & 29.5 & $1.46(\mathrm{~m})$ & 29.5 & $1.49(\mathrm{~m})$ \\
\hline & & $2.08(\mathrm{~m})$ & & $2.11(\mathrm{~m})$ \\
\hline 3 & 76.8 & $4.06(\mathrm{~m})$ & 76.7 & $4.02(\mathrm{~m})$ \\
\hline 4 & 151.7 & & 151.6 & \\
\hline 5 & 47.9 & $2.02(\mathrm{~m})$ & 47.9 & $2.05(\mathrm{~m})$ \\
\hline \multirow[t]{2}{*}{6} & 22.1 & $1.58(\mathrm{~m})$ & 22.1 & $1.60(\mathrm{~m})$ \\
\hline & & $1.77(\mathrm{~m})$ & & $1.77(\mathrm{~m})$ \\
\hline \multirow[t]{2}{*}{7} & 27.1 & $1.99(\mathrm{~m})$ & 27.2 & $1.95(\mathrm{~m})$ \\
\hline & & $2.71(\mathrm{~m})$ & & $2.70(\mathrm{~m})$ \\
\hline 8 & 128.9 & & 128.9 & \\
\hline 9 & 140.8 & & 140.8 & \\
\hline 10 & 40.6 & & 40.6 & \\
\hline \multirow[t]{2}{*}{11} & 24.6 & $2.12(\mathrm{~m})$ & 24.6 & $2.17(\mathrm{~m})$ \\
\hline & & $2.28(\mathrm{~m})$ & & $2.29(\mathrm{~m})$ \\
\hline \multirow[t]{2}{*}{12} & 34.1 & $1.70(\mathrm{~m})$ & 34.0 & $1.70(\mathrm{~m})$ \\
\hline & & $2.19(\mathrm{~m})$ & & $2.21(\mathrm{~m})$ \\
\hline 13 & 47.5 & & 47.5 & \\
\hline 14 & 68.0 & & 68.1 & \\
\hline 15 & 73.3 & $4.60(\mathrm{~d}, 6.8)$ & 73.4 & $4.62(d, 6.8)$ \\
\hline \multirow[t]{2}{*}{16} & 44.6 & $1.49(\mathrm{~m})$ & 44.6 & $1.47(\mathrm{~m})$ \\
\hline & & $2.66(\mathrm{~m})$ & & $2.68(\mathrm{~m})$ \\
\hline 17 & 51.8 & $1.44(\mathrm{~m})$ & 51.8 & $1.45(\mathrm{~m})$ \\
\hline 18 & 18.9 & $1.11(\mathrm{~s})$ & 19.0 & $1.11(\mathrm{~s})$ \\
\hline 19 & 19.4 & $0.93(\mathrm{~s})$ & 19.4 & $0.95(\mathrm{~s})$ \\
\hline 20 & 36.7 & $1.60(\mathrm{~m})$ & 36.7 & $1.60(\mathrm{~m})$ \\
\hline 21 & 19.2 & $0.96(d, 6.5)$ & 19.2 & $0.97(d, 6.4)$ \\
\hline \multirow[t]{2}{*}{22} & 36.1 & $1.16(\mathrm{~m})$ & 36.1 & $1.18(\mathrm{~m})$ \\
\hline & & $1.57(\mathrm{~m})$ & & $1.58(\mathrm{~m})$ \\
\hline \multirow[t]{2}{*}{23} & 31.9 & $1.92(\mathrm{~m})$ & 32.0 & $1.92(\mathrm{~m})$ \\
\hline & & $2.10(\mathrm{~m})$ & & $2.11(\mathrm{~m})$ \\
\hline 24 & 157.7 & & 157.7 & \\
\hline 25 & 34.9 & 2.24 (hept.) & 34.9 & 2.25 (septet, 6.6) \\
\hline 26 & 22.3 & $1.03(\mathrm{~d}, 6.5)$ & 22.3 & $1.03(d, 6.6)$ \\
\hline 27 & 22.5 & $1.03(\mathrm{~d}, 6.5)$ & 22.5 & $1.05(\mathrm{~d}, 6.6)$ \\
\hline \multirow[t]{2}{*}{28} & 106.9 & $4.65(\mathrm{~s})$ & 106.9 & $4.67(\mathrm{~s})$ \\
\hline & & $4.72(\mathrm{~s})$ & & $4.73(\mathrm{~s})$ \\
\hline \multirow[t]{2}{*}{29} & 104.4 & $4.65(\mathrm{~s})$ & 104.5 & $4.68(\mathrm{~s})$ \\
\hline & & 5.19 (brs) & & $5.26(\mathrm{~s})$ \\
\hline 30 & 179.3 & & 179.4 & \\
\hline $1^{\prime}$ & 96.8 & $4.98(d, 3.6)$ & 96.9 & $5.01(d, 4.0)$ \\
\hline $2^{\prime}$ & 73.7 & $3.41(\mathrm{dd}, 3.6,9.7)$ & 73.6 & $3.42(\mathrm{dd}, 3.8,9.5)$ \\
\hline $3^{\prime}$ & 75.2 & $3.84(\mathrm{dd}, 9.0,9.6)$ & 75.2 & $3.77(\mathrm{dd}, 9.5,9.5)$ \\
\hline $4^{\prime}$ & 81.2 & $3.10(\mathrm{dd}, 9.0,9.1)$ & 71.9 & $3.32(\mathrm{dd}, 9.5,9.5)$ \\
\hline $4^{\prime}-\mathrm{Me}$ & 60.8 & $3.55(\mathrm{~s})$ & & \\
\hline $5^{\prime}$ & 73.0 & $3.61(\mathrm{~d}, 9.1)$ & 74.0 & $3.66(\mathrm{~m})$ \\
\hline \multirow[t]{2}{*}{$6^{\prime}$} & 62.2 & $3.62(\mathrm{~m})$ & 62.7 & $3.66(\mathrm{~m})$ \\
\hline & & $3.69(\mathrm{~d}, 13.3)$ & & $3.73(\mathrm{~m})$ \\
\hline
\end{tabular}

Data were collected at $400 \mathrm{MHz}$ for ${ }^{1} \mathrm{H}$ and $100 \mathrm{MHz}$ for ${ }^{13} \mathrm{C}$. ${ }^{a}$ Literature data are from Weber et al. ${ }^{13}$
(4:1). 1 was obtained as a white powder. It was soluble in $\mathrm{CH}_{3} \mathrm{OH}$, acetonitrile, $\mathrm{H}_{2} \mathrm{O}$ and dimethyl sulfoxide but not in $n$-hexane. The $R_{\mathrm{f}}$ value in the solvent system $4: 1 \mathrm{CHCl}_{3}-\mathrm{CH}_{3} \mathrm{OH}$ was 0.46 on a TLC plate, silica gel $60 \mathrm{~F}_{254}$ (Merck KGaA, Darmstadt, Germany); $[\alpha]_{\mathrm{D}}{ }^{27}$ $+45.5^{\circ}\left(c=0.1, \mathrm{CH}_{3} \mathrm{OH}\right)$; IR; $\mathrm{KBr} \nu_{\max } 3482,2935,2873,1700,1639$, 1523, 1457 and $1029 \mathrm{~cm}^{-1}$; UV (MeOH) $\lambda_{\max } \mathrm{nm}(\varepsilon) 201$ (13923), 233 (sh, 3200). The molecular formula of 1 was determined to be $\mathrm{C}_{36} \mathrm{H}_{56} \mathrm{O}_{9}$ based on ESI-high-resolution mass spectrometry data ([M $\left.+\mathrm{NH}_{4}\right]^{+}, m / z$ 650.4249: calculated for $\mathrm{C}_{36} \mathrm{H}_{60} \mathrm{NO}_{9}, 650.4263$ ), requiring nine double-bond equivalents. The IR spectrum displayed carbonyl absorption at $1700 \mathrm{~cm}^{-1}$, suggesting the presence of a carboxyl group. All connections for $\mathrm{H}$ and $\mathrm{C}$ in $\mathbf{1}$ were elucidated by the gHSQC study. The NMR data and the molecular formula indicated the presence of 5 methyl, 10 methylene, $11 s p^{3}$ methine, 2 $s p^{2}$ exomethylene, $3 s p^{3}$ quaternary, $4 s p^{2}$ quaternary and 1 carbonyl carbons (Table 1). ${ }^{1} \mathrm{H}-{ }^{1} \mathrm{H}$ correlations in gCOSY for $\mathrm{H}-1^{\prime}$ through $\mathrm{H}-6^{\prime}$ indicated the presence of a sugar moiety including the anomeric proton (Figure 1b). ESI-MS/MS also supported the presence of a sugar moiety by key fragment ions at $\mathrm{m} / \mathrm{z} 471.3471[\mathrm{M}+\mathrm{H} \text {-sugar }]^{+}$and $453.3357\left[\mathrm{M}+\mathrm{H}-\mathrm{H}_{2} \mathrm{O} \text {-sugar }\right]^{+}$. The glycoside was determined to be glucose through analysis of the chemical shifts and coupling patterns of its proton signals. Furthermore, the small ${ }^{3} J_{\mathrm{H}-1^{\prime}, \mathrm{H}-2^{\prime}}$ value $(J=3.9$ $\mathrm{Hz}$ ) indicated the $\alpha$-glycoside. ${ }^{11}$ The remaining $\mathrm{C}_{30}$ unit was identified as a sterol-type triterpenoid aglycone, based on 2D NMR analysis. Further analysis of the gCOSY and gHMBC showed that the aglycone of 1 contains a carboxyl group at the C-14 position, two exocyclic methylene groups at C-4 and C-24 and a hydroxyl group at $\mathrm{C}-15$ of the aglycone (Figure $1 \mathrm{~b}$ ). The aglycone structure was the same as that of ascosteroside A, having a lanostane-type triterpenoid by comparison of the NMR data of $1 .^{12,13}$ In addition, linkage of the sugar to $\mathrm{C}-3$ of the aglycone was elucidated by ${ }^{1} \mathrm{H}-{ }^{13} \mathrm{C}$ long-range correlations from $\mathrm{C}-3$ methine proton to $\mathrm{C}-1^{\prime}$ and from $\mathrm{C}-1^{\prime}$ anomeric proton to $\mathrm{C}-3$. Therefore, based on the spectral data, the structure of 1 was elucidated as 4 "-O-demethylascosteroside A and named ascosteroside C. Although $\mathbf{1}$ is listed in the CAS Registry file (registry number 1059607-52-1), there are no published data or physico-chemical data.

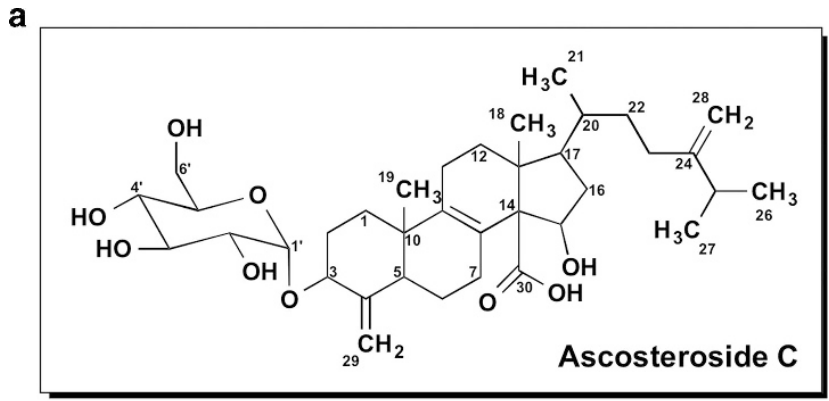

b

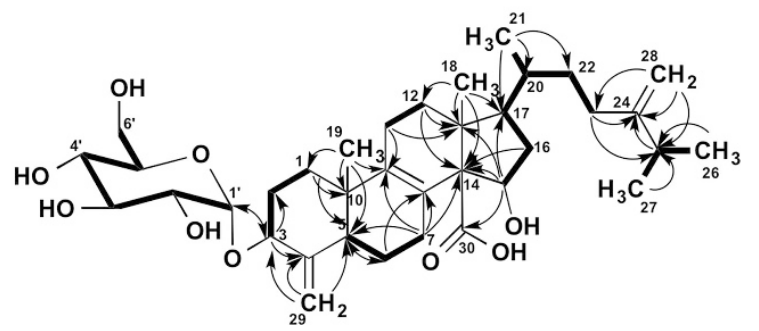

Figure 1 (a) Structure of ascosteroside C. (b) Key correlations of gCOSY and gHMBC in ascosteroside $\mathrm{C}$. 
a

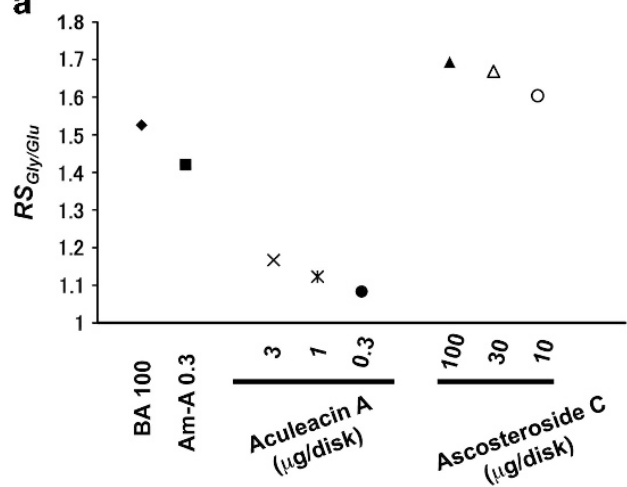

b

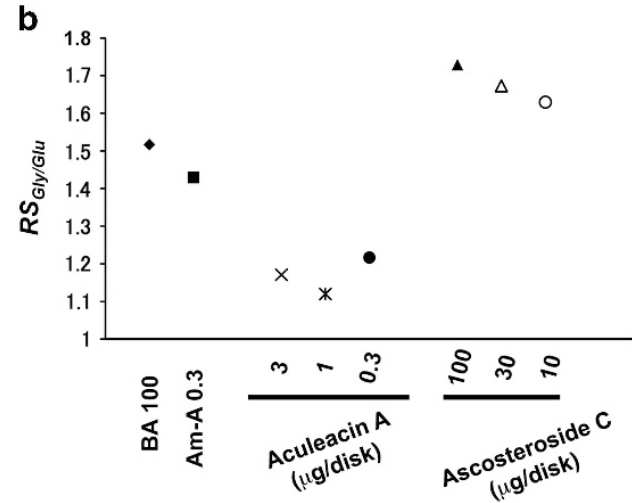

Figure 2 Selective growth inhibition activity of ascosteroside C. The logarithm of the inhibition zone in glycerol versus glucose provides a relative score $\left(\mathrm{RS}_{\mathrm{g}|\mathrm{y} / \mathrm{g}| \mathrm{u}}\right)$ for each compound. (a) Results of paper disk assays for the WB-12 pRS314YA2P/y2NtcAAC (glycerol-containing medium) and WB-12 pRS314YA2P (glucose-containing medium) strains. (b) Results of paper disk assays for the WB-12 pRS314YA2P/y2NapAAC and WB-12 pRS314YA2P strains. : $100 \mu \mathrm{g}$ per disk bongkrekic acid (BA 100), $\mathbf{0}$ : $0.3 \mu \mathrm{g}$ per disk antimycin A (Am-A 0.3), x: $3 \mu \mathrm{g}$ per disk aculeacin A, *: $1 \mu \mathrm{g}$ per disk aculeacin A, ๑: $0.3 \mu \mathrm{g}$ per disk aculeacin $\mathrm{A}, \mathbf{\Delta}: 100 \mu \mathrm{g}$ per disk ascosteroside $\mathrm{C}, \triangle \mathrm{:} 30 \mu \mathrm{g}$ per disk ascosteroside $\mathrm{C}, \mathrm{O}: 10 \mu \mathrm{g}$ per disk ascosteroside $\mathrm{C}$. RS, relative score.

The activities of the compounds were evaluated using $\Delta a a c$ yeast in a glucose-containing medium and insect aac-transformed yeasts in glycerol-containing yeasts. The former organisms cannot export ATP from mitochondria to cytosol and thus only grow in glucosecontaining media. The latter can grow in glycerol-containing media using transformed aac. The paper disk method was used to test the effects of compounds on growth of the WB-12 pRS314YA2P strain (endogenous AAC-disrupted and single-copy type yeast shuttle vector pRS314-YA2P-expressing strain) in glucose-containing medium and the WB-12 pRS314YA2P/y2NtcAAC strain (endogenous AAC-disrupted and Tribolium castaneum AAC-expressing strain, accession number XP_973257) or the WB-12 pRS314YA2P/ y2NapAAC (endogenous AAC-disrupted and Acyrthosiphon pisum AAC-expressing strain, accession number NM_001162030) in glycerol-containing medium. ${ }^{14,15}$

We evaluated the contribution of AAC to the growth inhibition using a relative score in both media $\left(\mathrm{RS}_{\mathrm{gly} / \mathrm{glu}}\right) . \mathrm{RS}_{\mathrm{gly} / \mathrm{glu}}$ was defined as the $\log _{10}$ ratio of the inhibition zone in glycerol divided by the inhibition zone in glucose. An $\mathrm{RS}_{\mathrm{gly} / \mathrm{glu}}$ score greater than 1.4 indicated that the tested compounds were selectively lethal or inhibited growth in glycerol-containing medium, including inhibitors of bongkrekic acid, antimycin A and 1. Aculeacin A's $\mathrm{RS}_{\text {gly/glu }}$ scores showed inhibition of yeast growth without affecting mitochondrial respiration in a glycerol- or glucose-containing medium (Figure 2).

At the molecular level, the direct targets for bongkrekic acid and antimycin A have been identified as the AAC and complex III, respectively. ${ }^{16-18}$ Thus, it appears that an inhibitor of mitochondrial respiration could selectively inhibit the growth of genetically modified S. cerevisiae strains in glycerol-containing medium.

As 1 showed a phenotype similar to mitochondrial respiration inhibitors, such as bongkrekic acid and antimycin A, we hypothesized that 1 might inhibit mitochondrial function. Recently, ascosteroside A was shown to inhibit $1,3-\beta$-D-glucan synthase in an in vitro assay. However, in our assay, aculeacin A, an echinocandin-like lipopeptide known to be an inhibitor of $1,3-\beta$-D-glucan synthase, did not show high $\mathrm{RS}_{\mathrm{gly} / \mathrm{glu}}$ (Figure 2). ${ }^{19}$ Thus, the mode of action of ascosteroside $\mathrm{C}$ in the growth inhibition of recombinant $S$. cerevisiae remains controversial to inhibit 1,3- $\beta$-D-glucan synthase.

We next examined the effect of $\mathbf{1}$ on the electron transfer activity of isolated mitochondria from wild-type S. cerevisiae. The rate of electron transfer was accelerated by a factor of $\sim 2.5$ by $10 \mu \mathrm{M}$ of 1 , indicating that this compound apparently elicits an uncoupling effect, although the mechanism of uncoupling activity remains unknown. It is reasonable to consider that the uncoupling activity, which brings about a decrease in the ATP synthesis by reducing electrochemical potential of protons, may be a cause of the inhibition of the growth of yeast.

Finally, to confirm the cytotoxic effect of 1, we performed cell growth inhibition assays using several tumor cell lines. HeLa S3 $\left(5 \times 10^{3}\right.$ cells per well), HT29 $\left(5 \times 10^{3}\right.$ cells per well $)$, A549 $\left(5 \times 10^{3}\right.$ cells per well), H1299 $\left(5 \times 10^{3}\right.$ cells per well $)$, HepG2 $\left(5 \times 10^{3}\right.$ cells per well) and Panc1 $\left(5 \times 10^{3}\right.$ cells per well $)$ cells were seeded in a 96-well microplate. Test compounds were dissolved in $\mathrm{MeOH}$ at appropriate concentrations and were treated for $48 \mathrm{~h}$. Cell proliferation assays were performed using the WST-8 (Nacalai Tesque, Kyoto, Japan) protocol. The absorbance $\left(A_{450}\right)$ of each well was measured using a Corona Grating Microplate Reader SH-9000 (Corona Electric Co. Ltd, Ibaraki, Japan). The results showed that $\mathbf{1}$ did not significantly inhibit cell growth or induce cell death at a concentration of $100 \mu \mathrm{m}$.

In conclusion, a mitochondrial respiration inhibitor $\mathbf{1}$ was isolated from the fungus Aspergillus sp., (strain FKI-6682) and its structure was elucidated to be a lanostane-type triterpenoid. Our data demonstrate that 1 inhibited the mitochondrial respiratory system in yeast, particularly yeast grown in glycerol medium. Further studies aimed at understanding the effects of this molecule will provide key insights into the development of new chemical pesticides.

\section{CONFLICT OF INTEREST}

The authors declare no conflict of interest.

\section{ACKNOWLEDGEMENTS}

The study was supported by the Programme for Promotion of Basic and Applied Researches for Innovations in Bio-oriented Industry from Bio-oriented Technology Research Advancement Institution, Japan. We are grateful to Dr Kenichiro Nagai and Ms Noriko Sato, School of Pharmacy, Kitasato University, for help in obtaining NMR and MS data and are grateful to Dr Rokuro Masuma, Dr Mihoko Mori and Dr Hidetaka Yuge, Kitasato University, for suggestions concerning the experiments. 
1 Herron, G., Jiang, L. \& Spooner-Hart, R. A laboratory-based method to measure relative pesticide and spray oil efficacy against the broad mite, Polyphagotarsonemus latus (Banks) (Acari: Tarsonemidae). Exp. Appl. Acarol. 20, 495-502 (1996).

2 Hayashi, N., Sasama, Y., Takahashi, N. \& Ikemi, N. Cyflumetofen, a novel acaricide-its mode of action and selectivity. Pest Manag. Sci. 69, 1080-1084 (2013).

3 Wakasa, F. \& Watanabe, S. Kanemite (acequinocyl): a new acaricide for control of various species of mites. Agrochem. Jpn 75, 17-20 (1999).

4 Kaufman, P. E., Rutz, D. A., Doscher, M. E. \& Albright, R. Efficacy of chlorfenapy (AC303630) experimental pour-on and CyLence formulations against naturally acquired louse infestations on cattle in New York. Vet. Parasitol. 97, 123-129 (2001).

$5 \mathrm{Kim}$, Y. J., Lee, S. H., Lee, S. W. \& Ahn, Y. J. Fenpyroximate resistance in Tetranychus urticae (Acari: Tetranychidae): cross-resistance and biochemical resistance mechanisms. Pest Manag. Sci. 60, 1001-1006 (2004).

6 Khalighi, M., Tirry, L. \& Van Leeuwen, T. Cross-resistance risk of the novel complex II inhibitors cyenopyrafen and cyflumetofen in resistant strains of the two-spotted spider mite Tetranychus urticae. Pest Manag. Sci. 70, 365-368 (2014).

7 Van Nieuwenhuyse, P. Van Leeuwen, T., Khajehali, J., Vanholme, B. \& Tirry, L. Mutations in the mitochondrial cytochrome b of Tetranychus urticae Koch (Acari: Tetranychidae) confer cross-resistance between bifenazate and acequinocyl. Pest Manag. Sci. 65, 404-412 (2009).

8 Herron, G. A. \& Rophail, J. First detection of chlorfenapyr (Secure) resistance in twospotted spider mite (Acari: Tetranychidae) from nectarines in an Australian orchard. Exp. Appl. Acarol. 31, 131-134 (2003).

9 Van Leeuwen, T., Vontas, J., Tsagkarakou, A., Dermauw, W. \& Tirry, L. Acaricide resistance mechanisms in the two-spotted spider mite Tetranychus urticae and other important Acari: a review. Insect Biochem. Mol. Biol. 40 563-572 (2010).

10 Altschul, S. F. et al. Gapped BLAST and PSI-BLAST: a new generation of protein database search programs. Nucleic Acids Res. 25, 3389-3402 (1997).

11 Asami, Y. et al. Isolation and synthesis of a new bioactive ellagic acid derivative from Combretum yunnanensis. J. Nat. Prod. 66, 729-731 (2003).

12 Leet, J. E., Huang, S., Klohr, S. E. \& McBrien, K. D. Ascosteroside, a new antifungal agent from Ascotricha amphitricha. II. Isolation and structure elucidation. J. Antibiot. 49, 553-559 (1996).

13 Weber, R. W., Kappe, R., Paululat, T., Mösker, E. \& Anke, H. Anti-Candida metabolites from endophytic fungi. Phytochemistry 68, 886-892 (2007).

14 Hashimoto, M. et al. Expression of the bovine heart mitochondrial ADP/ATP carrier in yeast mitochondria: significantly enhanced expression by replacement of the $\mathrm{N}$-terminal region of the bovine carrier by the corresponding regions of the yeast carriers. Biochim. Biophys. Acta 1409, 113-124 (1999).

15 Asami, Y. et al. RK-805, an endothelial cells growth inhibitor, produced by Neosartorya sp. Tetrahedron 60, 7085-7091 (2004).

16 Klingenberg, M. The state of ADP or ATP fixed to the mitochondria by bongkrekate. Eur J. Biochem. 65, 601-605 (1976).

17 Lauquin, G. J. \& Vignais, P. V. Interaction of $(3 \mathrm{H})$ bongkrekic acid with the mitochondrial adenine nucleotide translocator. Biochemistry 15, 2316-2322 (1976).

18 Jagow, V. G. \& Bohrer, C. Inhibition of electron transfer from ferrocytochrome $b$ to ubiquinone, cytochrome $\mathrm{cl}$ and duroquinone by antimycin. Biochim. Biophys. Acta 387, 409-424 (1975)

19 Mizoguchi, J., Saito, T., Mizuno, K. \& Hayano, K. On the mode of action of a new antifungal antibiotic, aculeacin A: inhibition of cell wall synthesis in Saccharomyces cerevisiae. J. Antibiot. 30, 308-313 (1977). 